\title{
Cationic DABCO-based Catalyst for Site-Selective C-H Alkylation via Photoinduced Hydrogen-Atom Transfer
}

\begin{abstract}
Akira Matsumoto*[a] and Keiji Maruoka*[a, b]
Abstract: A novel class of hydrogen-atom transfer (HAT) catalysts based on the readily available and tunable 1,4diazabicyclo[2.2.2]octane (DABCO) structure was designed, and their photoinduced HAT catalysis ability was demonstrated. The combination of the optimal HAT catalyst with an acridinium-based organophotoredox catalyst enables highly efficient and site-selective $\mathrm{C}-\mathrm{H}$ alkylation of substrates ranging from unactivated hydrocarbons to complex molecules. Notably, a HAT catalyst with additional substituents adjacent to a nitrogen atom further improved the siteselectivity. Mechanistic studies suggested that the $\mathrm{N}$-substituent of the catalyst plays a crucial role, assisting in the generation of a dicationic aminium radical as an active species for the HAT process.
\end{abstract}

The direct functionalization of carbon-hydrogen $(\mathrm{C}-\mathrm{H})$ bonds is a powerful strategy to achieve the facile synthesis of functional materials and pharmaceutical compounds in step- and atomeconomical manners. Hydrogen-atom transfer (HAT) is a promising approach in this area, and the recent progress that has been made by combining HAT with photochemistry has enabled diverse functionalizations of $\mathrm{C}-\mathrm{H}$ bonds that are difficult to activate by the classical methodologies. ${ }^{[1-2]}$ In order to predict the feasibility and selectivity of HAT catalysis, the bond dissociation energies (BDEs) of both the substrate and the catalyst are crucial thermodynamic parameters. ${ }^{[3]}$ Additionally, several kinetic factors (i.e., polarity and steric hindrance) also largely affect the reaction outcome. ${ }^{[4]}$ In some cases, these kinetic factors arising from the structure of the HAT catalyst can overcome the thermodynamic preference to determine the site-selectivity, although only a few examples have been reported so far. ${ }^{[5]}$ Hence, the development of novel HAT catalysts with different structural characteristics is important to expand the potential of HAT catalysis. ${ }^{[6]}$

Nitrogen-centered radicals are one type of attractive species that can be used for the HAT process. ${ }^{[7]}$ Among them, tertiary amine-derived cationic aminium radicals have recently been gaining attention as efficient HAT mediators. ${ }^{[8-9]}$ The highly electrophilic nature of these radicals enables the selective abstraction of a hydrogen atom from hydridic $\mathrm{C}-\mathrm{H}$ bonds. While aminium radicals derived from quinuclidine and its derivatives have been used for efficient HAT from substrates bearing $\mathrm{C}-\mathrm{H}$ bonds adjacent to a heteroatom, ${ }^{[8]}$ the more electrophilic dicationic aminium radical derived from Selectfluor ${ }^{\circledR}$ can even abstract hydrogen atoms from the unactivated $\mathrm{C}-\mathrm{H}$ bonds of hydrocarbons (Figure 1A) ${ }^{[9]}$ Moreover, these methods sometimes

[a] Dr. A. Matsumoto, Prof. Dr. K. Maruoka Graduate School of Pharmaceutical Sciences, Kyoto University, Sakyo, Kyoto 606-8501, Japan

E-mail: matsumoto.akira.3c@kyoto-u.ac.jp; maruoka.keiji.4w@kyoto-u.ac.jp

[b] Prof. Dr. K. Maruoka

School of Chemical Engineering and Light Industry, Guangdong University of Technology, Guangzhou 510006, China

Supporting information and the ORCID identification numbers for the authors of this article is given via a link at the end of the document.
A) Use of Selectfluor ${ }^{\circledR}$ as HAT reagent

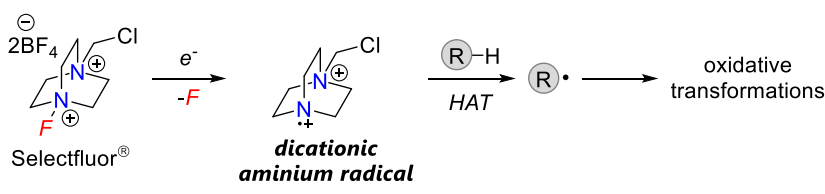

B) Cationic DABCO-based catalyst for photoinduced HAT (this work)

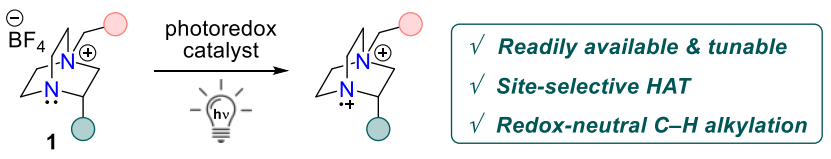

Figure 1. Generation of dicationic aminium radicals for HAT processes.

show unique site-selectivity among $\mathrm{C}-\mathrm{H}$ bonds with similar BDEs. ${ }^{[10]}$ Despite these attractive features, the use of dicationic aminium radicals as HAT mediators has been limited to fluorination and a few other oxidative transformations, as this radical is mainly generated in situ from a (supra)stoichiometric amount of Selectfluor ${ }^{\circledR}$, which is known as a fluorine-atom transfer reagent and/or a strong oxidant. ${ }^{[11]}$ Thus, the utility of this type of radicals in HAT catalysis under milder, redox-neutral conditions has not been explored. Herein, we describe a novel method for the catalytic use of dicationic aminium radicals in a photoinduced HAT process. The efficient generation of a dicationic aminium radical via single-electron transfer (SET) from monocationic tertiary amine 1 was achieved by using an organic photoredox catalyst under visible-light irradiation (Figure 1B). This method was successfully applied for the site-selective $\mathrm{C}-\mathrm{H}$ alkylation of a wide range of substrates, including natural products and bioactive molecules.

We commenced our study by synthesizing 1 with a series of substituents at the quaternary ammonium moiety (Table 1). One of the advantages of the present approach is the facile and modular synthesis of the catalyst structure: 1 can be prepared from inexpensive 1,4-diazabicyclo[2.2.2]octane (DABCO) and various alkyl/benzyl halides without purification by column chromatography (see the Supporting Information). The efficiency of compounds 1 as HAT catalysts was then evaluated by applying them to the photoinduced $\mathrm{C}-\mathrm{H}$ alkylation of cyclohexane with benzalmalononitrile (2) as a radical acceptor in the presence of acridinium photoredox catalyst (Mes-Acr ${ }^{+}$) under irradiation by a blue light-emitting diode (LED). ${ }^{[12]}$ The reaction with $\mathrm{N}$ chloromethyl-substituted derivative 1a, which forms the same dicationic aminium radical as Selectfluor ${ }^{\circledR}$ after the SET process, afforded the alkylated product 3 in low yield (entry 1). We found that changing the $\mathrm{N}$-substituent to a benzyl group improved both the conversion of $\mathbf{2}$ and the yield of $\mathbf{3}$ (entry 2). Although the steric profile of the $\mathrm{N}$-substituent of the catalyst is not likely to affect the efficiency of the HAT process, as it is located at the back side of the catalytic center, we speculated that the structure of the $N$ substituent would be associated with the efficiency of the SET process between $\mathbf{1}$ and the photoredox catalyst to generate the active radical species. Thus, other catalysts bearing a variety of 
Table 1: Screening of HAT catalyst for $\mathrm{C}-\mathrm{H}$ alkylation with $2{ }^{\text {[a] }}$

\begin{tabular}{|c|c|c|c|c|}
\hline $\mathrm{Me}^{\prime}$ & $+\mathrm{Ph}^{\prime}$ & $\begin{array}{l}\mathrm{CN} \\
\mathrm{CN}\end{array}$ & $\left.\begin{array}{c}\text { es-Acr }{ }^{+}(5.0 \mathrm{~mol} \%) \\
\mathbf{1}(10 \mathrm{~mol} \%)\end{array}\right)$ & $\begin{array}{l}\sum_{3(\mathrm{R}=\mathrm{Cy})}^{\mathrm{R}}{ }_{\mathrm{CN}}^{\mathrm{CN}} \\
4\left(\mathrm{R}=\mathrm{C}_{5} \mathrm{H}_{11}\right)^{[\mathrm{b}]}\end{array}$ \\
\hline Entry & Substrate & Catalyst & $\begin{array}{l}\text { Conversion } \\
\text { of } \mathbf{1}[\%]^{[c]}\end{array}$ & $\begin{array}{c}\text { Product } \\
{\left[\text { [yield, \%] }^{[c]}\right.}\end{array}$ \\
\hline 1 & \multirow{8}{*}{ Cyclohexane } & $1 a$ & 17 & $3(14)$ \\
\hline 2 & & $1 b$ & 42 & $3(34)$ \\
\hline 3 & & 1c & 99 & $3(93)$ \\
\hline 4 & & 1d & 9 & $3(9)$ \\
\hline 5 & & $1 e$ & 43 & $3(35)$ \\
\hline 6 & & $1 f$ & 24 & $3(24)$ \\
\hline 7 & & $1 \mathrm{~g}$ & 99 & $3(89)$ \\
\hline 8 & & $1 \mathrm{~h}$ & 99 & $3(95)$ \\
\hline 9 & \multirow{3}{*}{ Pentane } & 1c & 50 & $4(46)$ \\
\hline 10 & & $1 \mathrm{~g}$ & 86 & $4(80)$ \\
\hline 11 & & $1 \mathrm{~h}$ & 99 & $4(95)$ \\
\hline
\end{tabular}

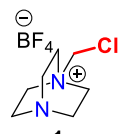

1a

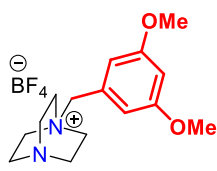

$1 d$

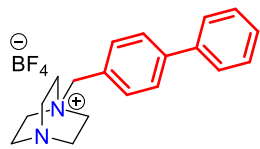

$1 \mathrm{~g}$

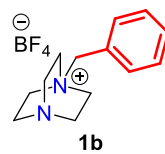

1b

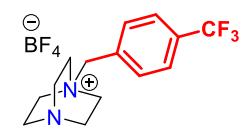

1e

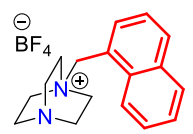

1h

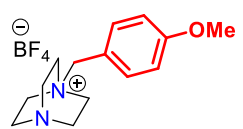

$1 c$

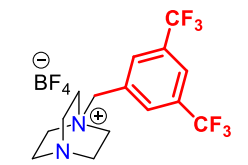

$1 f$

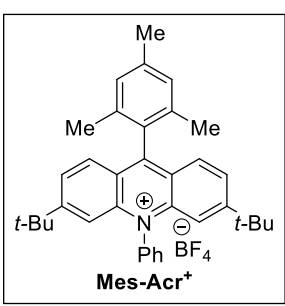

[a] Reactions were carried out using $\mathrm{C}-\mathrm{H}$ substrate $(0.60 \mathrm{mmol}), 2(0.20$ $\mathrm{mmol})$, Mes-Acr ${ }^{+}(5.0 \mathrm{~mol} \%)$, and 1 (10 mol\%) in degassed MeCN $(2.0$ $\mathrm{mL}$ ) under light irradiation (blue LED, $448 \mathrm{~nm}$ ) at $25^{\circ} \mathrm{C}$ for $11 \mathrm{~h}$. [b] Mixture of regio- and diastereoisomers. [c] Conversion and yield were determined by ${ }^{1} \mathrm{H}$ NMR using 1,1,2,2-tetrachloroethane as an internal standard.

$\overline{N \text {-substituents were also investigated to find a more suitable }}$ catalyst structure. Fortunately, tertiary amines bearing 4methoxyphenyl- (1c), 4-biphenyl- (1g), and 1-naphthyl (1h) groups exhibited high catalytic activity to furnish 3 in excellent yields (entries 3, 7, and 8). In contrast, catalysts with highly electron-rich (1d) or electron-deficient (1e-f) benzylic moieties showed unsatisfactory results (entries 4-6). Next, the three catalysts (1c, 1g, and $\mathbf{1 h}$ ) with high catalytic activity toward cyclohexane were tested using pentane as a representative acyclic hydrocarbon substrate to determine the optimal catalyst structure (entries 9-11). While catalysts 1c and $\mathbf{1 g}$ showed incomplete conversion of $\mathbf{2}$, the use of $\mathbf{1 h}$ led to full conversion of 2 with a nearly quantitative yield of 4 .
Having determined the optimal catalyst structure, the substrate scope for the photoinduced $\mathrm{C}-\mathrm{H}$ alkylation was investigated (Figure 2). In general, a broad range of $\mathrm{C}-\mathrm{H}$ substrates were applicable for reaction with $\mathbf{2}$ catalyzed by $\mathbf{1 h}$ to provide the corresponding alkylated products in good to excellent yields. Cyclic hydrocarbons other than cyclohexane gave the desired products $\mathbf{3}$ and $\mathbf{5}$ almost quantitatively. Cyclododecane was also applicable in this protocol, although its relatively low solubility in acetonitrile slightly lowered the yield of 6 . Acyclic hydrocarbons such as pentane and isopentane afforded a mixture of regio- and diastereoisomers of the alkylated products with excellent combined yields. Despite the fact that the $\mathrm{C}-\mathrm{H}$ bond of toluene is much weaker (BDE $=89 \mathrm{kcal} / \mathrm{mol}$ ) than those of hydrocarbons such as cyclohexane (BDE $=99 \mathrm{kcal} / \mathrm{mol})$, a greater amount of toluene was required to achieve a sufficient yield of 8. Various compounds with hydridic $\mathrm{C}-\mathrm{H}$ bonds adjacent to a heteroatom, such as alcohols, ethers, aldehydes, and a protected amine, were found to be suitable substrates for the present HAT catalytic system, affording the desired products 9-14 in good to excellent yields. Specifically, while the $\alpha-C-H$ alkylation of alcohols catalyzed by quinuclidine derivatives often requires co-catalysts to weaken the target $\mathrm{C}-\mathrm{H}$ bond, ${ }^{[13]}$ using our method based on a highly electrophilic aminium radical, the reactions proceeded smoothly to furnish the desired products $\mathbf{9}$ and $\mathbf{1 0}$ without the assistance of any co-catalyst. Moreover, the present system was applicable to an $\alpha, \beta$-unsaturated aldehyde; this class of aldehyde is less explored as substrates for HAT catalysis compared with aliphatic and aromatic aldehydes. ${ }^{[14]}$ In this case, catalyst 1c gave a slightly better yield of the desired product 13 than $\mathbf{1 h}$. In addition to the various $\mathrm{C}-\mathrm{H}$ substrates, the use of several electron-deficient olefins as radical acceptors was also investigated. The alkylation of cyclohexane with dimethyl fumarate, diethyl benzylidenemalonate, 1,1bis(phenylsulfonyl)ethylene, and ethyl coumarin-3-carboxylate proceeded to give the corresponding products 15-18 in moderate to high yields. Although the use of simple acrylates resulted in low yields of the alkylated products, we found that 1,1,1,3,3,3hexafluoroisopropyl acrylate worked well to afford 19, which was directly transformed into benzyl ester $\mathbf{2 0}$ or benzyl amide $\mathbf{2 1}$ in one-pot fashion (see the Supporting Information).

Subsequently, substrates containing more than two potentially reactive $\mathrm{C}-\mathrm{H}$ bonds were explored to evaluate the site-selectivity of the $\mathrm{C}-\mathrm{H}$ alkylation using the developed dicationic aminium radical. After an extensive study, we found that HAT preferentially takes place from the less sterically hindered $\mathrm{C}-\mathrm{H}$ bond rather than the more hindered $\mathrm{C}-\mathrm{H}$ bond in the same ether substrate. For instance, 2-methyltetrahydrofuran successfully underwent selective HAT at the secondary etheric $\mathrm{C}-\mathrm{H}$ bond using $\mathbf{1 h}$ to afford the alkylated product 22. Notably, the potential product derived from alkylation at the tertiary etheric $\mathrm{C}-\mathrm{H}$ bond with the weakest BDE was not detected at all. The HAT alkylation of 3methyltetrahydrofuran also proceeded selectively to furnish 23 along with a small amount of minor regioisomers (r.r. =10:1). As a notable example, 1-phenylethyl methyl ether has two etheric $\mathrm{C}-\mathrm{H}$ bonds, one of which is further activated by the adjacent phenyl group. Nevertheless, the reaction using $\mathbf{1 h}$ proceeded at the primary etheric $\mathrm{C}-\mathrm{H}$ bond to give the product $\mathbf{2 4}$ exclusively, with the weaker benzylic $\mathrm{C}-\mathrm{H}$ bond remining intact. On the other hand, the use of cyclopentyl methyl ether as the $\mathrm{C}-\mathrm{H}$ substrate led to the formation of $\mathbf{2 5}$ with moderate regioselectivity. At this point, we envisioned that the use of a more sterically demanding 


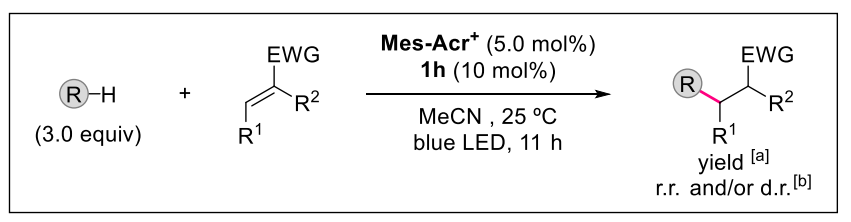

Hydrocarbon<smiles>N#CC(C#N)C(c1ccccc1)C1CCCCC1</smiles>

$98 \%$<smiles>N#CC(C#N)C(c1ccccc1)C1CCCCCCC1</smiles>

$98 \%$<smiles>N#CC(C#N)C(c1ccccc1)C1CCCCCCCCCCC1</smiles>

6

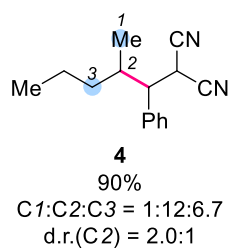

d.r. $(C 2)=2 \cdot 0: 1$<smiles>CCC(C)(C)C(c1ccccc1)C(C#N)C(C)C#N</smiles>

7
$99 \%$

C1:C2 = 5.3:1

d.r. $(\mathrm{C} 2)=1.1: 1$

Alcohol

Aldehyde<smiles>CCCC(O)C(c1ccccc1)C(C#N)C#N</smiles><smiles>CC(C)(O)C(c1ccccc1)C(C#N)C#N</smiles><smiles>N#CC(C#N)C(C(=O)c1ccccc1)c1ccccc1</smiles>

12
$98 \%$<smiles>C/C=C/C(=O)C(c1ccccc1)C(C#N)C#N</smiles>

Amine

Boc- $\mathrm{NH} \mathrm{CN}$<smiles>CCC(C)C(O)C(C)C#N</smiles>

14

$99 \%$ d. $r=1.5: 1$

Radical Acceptor<smiles>CCOC(=O)C(C(=O)OCC)C(c1ccccc1)C1CCCCC1</smiles>

15 16
$47 \%$ 17
$77 \%$<smiles>CCOC(=O)C1C(=O)Oc2ccccc2C1C1CCCCC1</smiles>

18
$81 \%$
$\overbrace{O}^{\sim} \underbrace{C F_{3}}_{C_{3}} \underset{\text { one-pot }{ }^{[f]}}{\stackrel{D B U, Z-H}{\longrightarrow}}$ 19
$\%(N M R)$<smiles>N#CC(C#N)C(Cc1ccccc1)c1ccccc1</smiles>

8

$6 \%[c]$<smiles>[Z]C(=O)CCC1CCCCC1</smiles>

$\mathrm{Z}=\mathrm{OBn}(\mathbf{2 0}): 85 \%$ NHBn (21): $73 \%$

Site-Selective C-H Alkylation

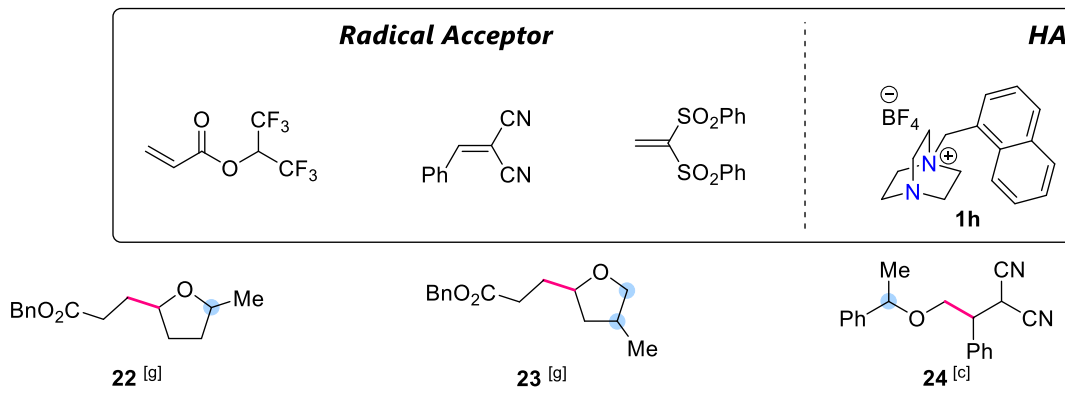

HAT Catalyst

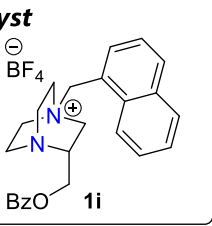

$\mathrm{BzO}$

$r>19: 1, d r=1.7: 1 \quad w / 1 h: 81 \%, r r=10: 1, d r=1.7: 1$

w/ 1h : $89 \%$, r.r. $>19: 1$, d.r. $=1.0: 1$

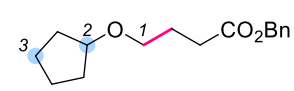

25 [g]

$\mathrm{w} / \mathrm{1h}: 87 \%, \mathrm{C} 1 \cdot \mathrm{C} 2 \cdot \mathrm{C} 3=3.4 \cdot 1 \cdot 2$ w/ 1i : $90 \%, C 1: C 2: C 3=18: 1: 4.0$

w/ 1 h : $99 \%$, r.r. $>19: 1$, d.r. $=17: 1$

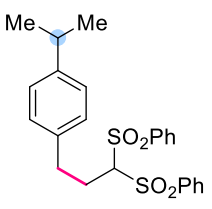

27 [h]

26 [g]

w/ $1 \mathrm{~h}: 81 \%$, r.r. $=5.4: 1$

$\mathrm{w} / \mathbf{1 i}: 82 \%$, r.r. $=18: 1$ $\mathbf{w} / 1 \mathbf{i}: 60 \%$, r.r. $=12: 1$

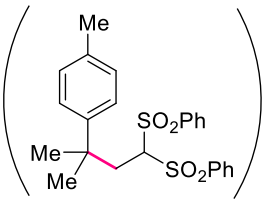

27' w/ 1 h : $68 \%$, r.r. $=7.0: 1$

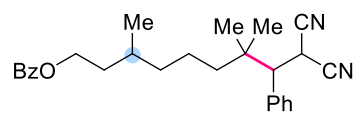

$28^{[c]}$

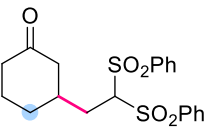

29 [h]

Figure 2. Scope of the photoinduced $\mathrm{C}-\mathrm{H}$ alkylation. [a] Combined isolated yields of all the isomers are shown. [b] Regioisomer ratio (r.r.) and diastereomer ratio (d.r.) were determined by ${ }^{1} \mathrm{H}$ NMR of the crude product. [c] With 5.0 equiv of the $\mathrm{C}-\mathrm{H}$ substrate. [d] Cyclized product was isolated after silica-gel column chromatography. [e] 1c was used as the HAT catalyst. [f] See the Supporting Information for details. [g] With 20 equiv of the C-H substrate. [h] With 10 equiv of the $\mathrm{C}-\mathrm{H}$ substrate.

catalyst would further improve the site-selectivity favoring HAT at the less hindered primary etheric $\mathrm{C}-\mathrm{H}$ bond. Thus, the novel catalyst $1 \mathbf{i}$ with an additional substituent adjacent to the nitrogen atom was synthesized and applied to the same transformation. As expected, the product of alkylation at the tertiary carbon (C2) was suppressed, which encouraged us to further investigate $\mathbf{1 i}$ as a superior catalyst to $\mathbf{1 h}$ for site-selective HAT alkylation. secButyl methyl ether also has primary and tertiary etheric $\mathrm{C}-\mathrm{H}$ bonds, and its HAT alkylation using $\mathbf{1 h}$ gave $\mathbf{2 6}$ as the major product with moderate regioselectivity. The replacement of HAT catalyst $\mathbf{1 h}$ with $\mathbf{1 i}$ resulted in a significant increase in regioselectivity (r.r. $=5.4: 1$ to $18: 1)$. In addition, $p$-cymene, which has both a primary and a tertiary benzylic $\mathrm{C}-\mathrm{H}$ bond, was examined as a benzylic substrate for the reaction with 1,1bis(phenylsulfonyl)ethylene. The major product $\mathbf{2 7}$ derived from alkylation at the less sterically hindered benzylic $\mathrm{C}-\mathrm{H}$ bond was 

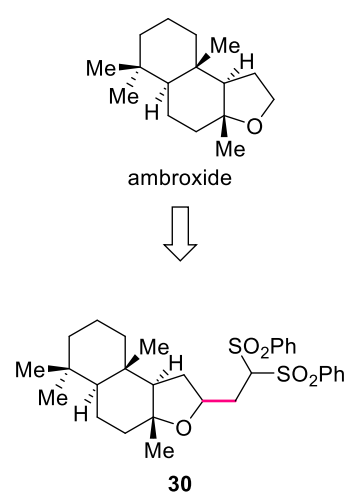

$78 \%$, r.r. $>19: 1$, d.r. $=2.0: 1$

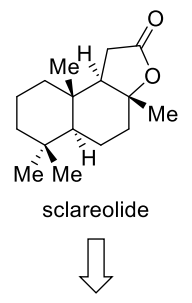

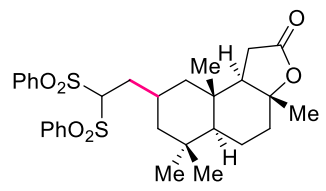

31

$81 \%$, r.r. $>19: 1$, d.r. $>19: 1$
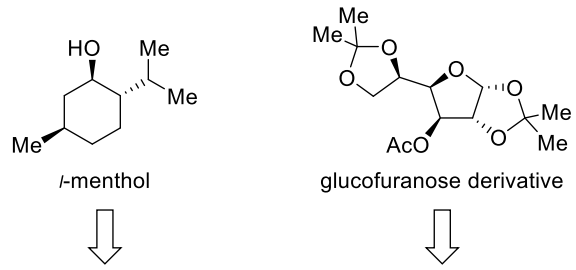

glucofuranose derivative<smiles>C1=CC=C1</smiles>
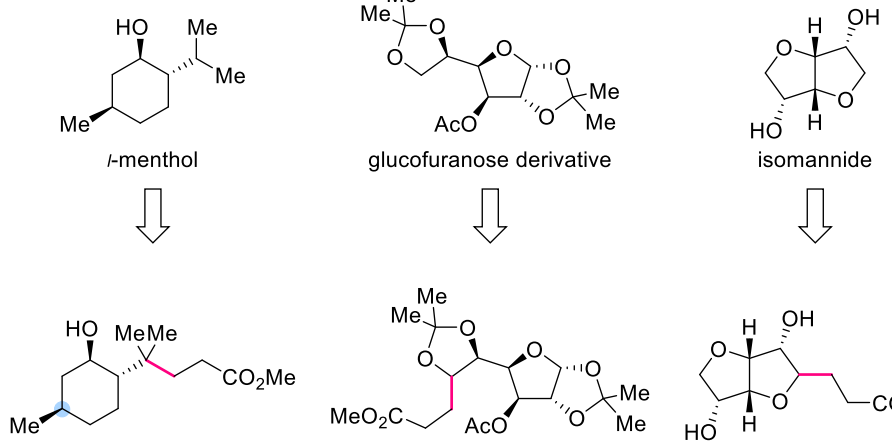

32

$88 \%$, r.r. $=10: 1$

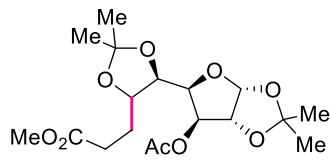

33

$77 \%$, r.r. $>19: 1$, d.r. $=3.2: 1$

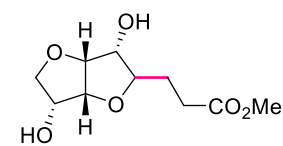

34

$60 \%$, r.r. $>19: 1$, d.r. $>19: 1$

Figure 3. Photoinduced $\mathrm{C}-\mathrm{H}$ alkylation of complex molecules. Reactions were carried out using substrate $(0.60 \mathrm{mmol})$, radical acceptor (0.20 mmol), Mes-Acr ${ }^{+}$ $(5.0 \mathrm{~mol} \%)$, and $\mathbf{1 h}(10 \mathrm{~mol} \%)$ in degassed $\mathrm{MeCN}(1.0 \mathrm{~mL})$ under light irradiation (blue LED, $448 \mathrm{~nm})$ at $25^{\circ} \mathrm{C}$ for $11 \mathrm{~h}$.

obtained with good regioselectivity, which was successfully increased by changing the catalyst from $1 \mathbf{h}$ to $1 \mathbf{i}$ (r.r. $=7.0: 1$ to 12:1). Interestingly, Knowles and Alexanian et al. recently reported that $\mathrm{C}-\mathrm{H}$ alkylation using the same substrate and radical acceptor with a phosphate base as a HAT catalyst exclusively furnished 27', which results from selective HAT at the tertiary benzylic $\mathrm{C}-\mathrm{H}$ bond. ${ }^{[15]}$ These contrasting results emphasize the importance of developing novel catalyst designs for control of the site-selectivity in HAT catalysis. ${ }^{[5]}$ Although the structure of 1i was not optimized and its positive effect on the site-selectivity was still limited, further investigations toward the development of a more general and highly selective HAT catalyst are underway in our laboratory. In addition to ether and benzylic substrates, compounds with unactivated $\mathrm{C}-\mathrm{H}$ bonds were also competent substrates for the site-selective $\mathrm{C}-\mathrm{H}$ alkylation. When O-benzoyl dihydrocitronellol, which has two tertiary $\mathrm{C}-\mathrm{H}$ bonds, was subjected to our method using $\mathbf{1 h}$, the remote and more electron-rich tertiary $\mathrm{C}-\mathrm{H}$ bond was selectively alkylated to give the product 28 . In the case of cyclohexanone, $\beta-\mathrm{C}-\mathrm{H}$ alkylation proceeded to afford 29 with good regioselectivity.

To demonstrate the applicability of our method for the latestage functionalization of natural products and biologically active compounds, the site-selective $\mathrm{C}-\mathrm{H}$ alkylation of complex molecules was carried out (Figure 3). Ambroxide and sclareolide, both of which are representative targets for $\mathrm{C}-\mathrm{H}$ functionalization reactions, were well tolerated by the present system to deliver $\mathbf{3 0}$ and 31, respectively, with high yields and regioselectivities. LMenthol was successfully applied without protection of the hydroxy group. In this case, the $\alpha-\mathrm{C}-\mathrm{H}$ bond relative to the hydroxy group did not react, probably due to the sterically hindered environment. Instead, the tertiary $\mathrm{C}-\mathrm{H}$ bond in the isopropyl moiety was preferentially alkylated to provide $\mathbf{3 2}$ in high yield. While sugar derivatives have multiple reactive $\mathrm{C}-\mathrm{H}$ bonds adjacent to oxygen atoms, a suitably protected derivative of glucofuranose selectively afforded $\mathbf{3} 3$ as a single product. Finally, the polyoxygenated compound isomannide was selectively alkylated to give $\mathbf{3 4}$ in good yield.

To better understand the reaction mechanism, several experiments and analytical studies were conducted (Figure 4). Stern-Volmer fluorescence quenching studies confirmed that only $\mathbf{1 h}$ quenches the excited state of Mes-Acr+, and that the other reaction components do not (Figure 4a). Cyclic voltammetry $(\mathrm{CV})$ measurement of $\mathbf{1 h}$ showed the occurrence of an ambiguous peak at $+1.7 \mathrm{~V}$ vs the saturated calomel electrode (SCE). To obtain more information about the oxidation potential

(a) Stern-Volmer quenching studies

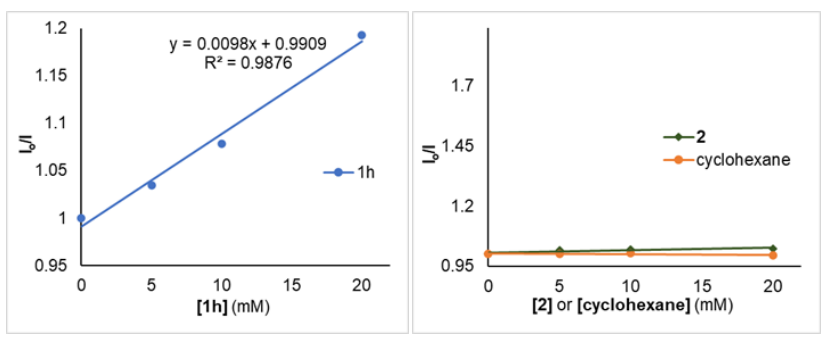

(b) Cyclic voltammetry studies

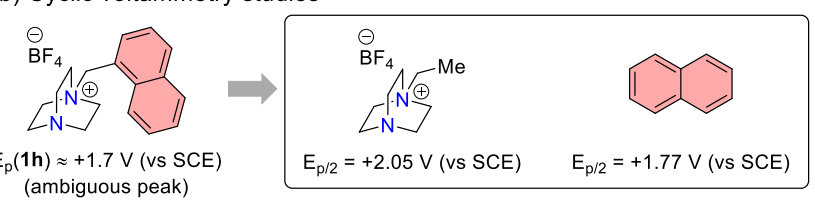

(c) Calculated $\mathrm{N}^{+}-\mathrm{H}$ BDE

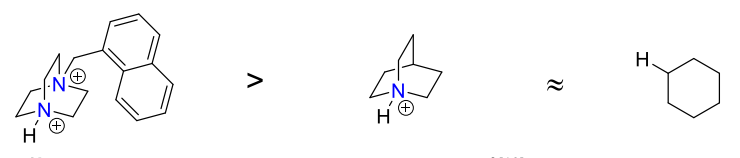

$\operatorname{BDE}(\mathbf{1} \cdot \mathrm{H})=106 \mathrm{kcal} / \mathrm{mol} \quad \mathrm{BDE}=100 \mathrm{kcal} / \mathrm{mol}^{\mathrm{ref}}[16] \quad \mathrm{BDE}=99 \mathrm{kcal} / \mathrm{mo}$

(d) Effect of $N$-substituent

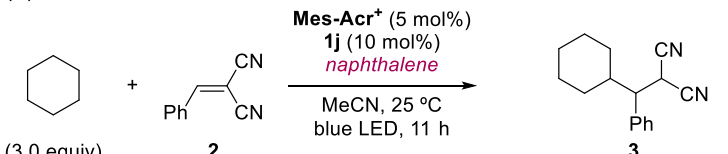

(3.0 equiv)

w/o naphthalene $: 17 \%$ wio

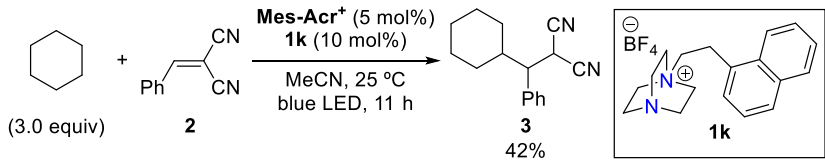

Figure 4. Mechanistic studies. 
of $1 \mathrm{~h}$, the same measurements were conducted using naphthalene and the $N$-ethyl substituted catalyst $\mathbf{1 j}$, which exhibited the half-peak potentials $\left(E_{p / 2}\right)$ of $+1.77 \mathrm{~V}$ vs SCE and $+2.05 \mathrm{~V}$ vs SCE, respectively (Figure 4b). ${ }^{[16]}$ These results suggest that both the tertiary amine and naphthalene moieties of $1 \mathrm{~h}$ can be oxidized by the excited state of Mes-Acr ${ }^{+}$via reductive quenching $\left({ }^{*} \mathrm{E}_{1 / 2}{ }^{\text {red }}=+2.15 \mathrm{~V}\right.$ vs SCE $),{ }^{[12]}$ but the naphthalene moiety would be oxidized more efficiently than the tertiary amine moiety. Based on these experimental results, DFT calculations of each catalyst 1 were then carried out (Figure 4c, for details of DFT computation see page S33 of the Supporting Information). The BDE value for the $\mathrm{N}^{+}-\mathrm{H}$ bond of the protonated form of $\mathbf{1 h}$ was evaluated to be $106 \mathrm{kcal} / \mathrm{mol}$, and those for other catalysts, except for 1d, were found to be within the range of 104-109 $\mathrm{kcal} / \mathrm{mol}$ (see the Supporting Information for BDE of all catalysts). These results indicate that the dicationic aminium radicals generated from 1 have greater reactivity than the structurally analogous quinuclidinium radical $(\mathrm{BDE}=100 \mathrm{kcal} / \mathrm{mol}),{ }^{[17]}$ which is consistent with the efficient HAT from unactivated hydrocarbons such as cyclohexane $(\mathrm{BDE}(\mathrm{C}-\mathrm{H})=99 \mathrm{kcal} / \mathrm{mol})$ using 1. Next, we investigated the role of the $\mathrm{N}$-substituent in catalyst 1 (Figure $4 d$ ). The reaction of cyclohexane with 2 using $\mathbf{1 j}$ as the catalyst provided $\mathbf{3}$ in $17 \%$ yield, which is similar to that obtained using $\mathrm{N}$-chloromethyl substituted catalyst 1a (Table 1 , entry 1). The addition of $10 \mathrm{~mol} \%$ or $100 \mathrm{~mol} \%$ of naphthalene in the same system had no positive effect on the product yield. On the other hand, catalyst $\mathbf{1 k}$ bearing a naphthalene moiety tethered with an elongated linker showed intermediate reactivity relative to those of $\mathbf{1 h}$ and $\mathbf{1 j}$. Based on these results, we speculate that the aromatic group tethered to the quaternary ammonium moiety in the catalyst would act as a redox mediator, assisting in the efficient generation of the dicationic aminium radical as a key radical species via intramolecular electron transfer. Finally, other investigations such as radical-inhibition experiments and deuterium-labeling studies provided evidence supporting the mechanism involving HAT by the in situgenerated dicationic aminium radical (see the Supporting Information for details).

Based on these experiments, a plausible reaction mechanism using the optimal catalyst $\mathbf{1 h}$ is described in Figure 5 . The catalytic cycle is initiated by the single-electron oxidation of catalyst $\mathbf{1 h}$ by the excited state of the acridinium catalyst (Mes$\mathrm{Acr}^{+\star}$ ), which is generated via visible-light irradiation. The direct oxidation of the tertiary amine moiety of $\mathbf{1 h}$ to form dicationic aminium radical $\mathbf{B}$ is possible, but less efficient. Instead, if the catalyst has a suitable aromatic moiety as a redox mediator on its $\mathrm{N}$-substituent, the oxidation preferentially takes place at the aromatic ring to form the transient intermediate A. ${ }^{[18]}$ Subsequent intramolecular electron transfer from the nitrogen atom to the aromatic ring furnishes $\mathbf{B}$ as the active radical species, which abstracts the hydrogen atom from the $\mathrm{C}-\mathrm{H}$ bond of the substrate. ${ }^{[19]}$ The resultant nucleophilic radical reacts with the electron-deficient alkene to form a new $\mathrm{C}-\mathrm{C}$ bond. Subsequent SET from the reduced form of the acridinium catalyst (Mes-Acr) to the electrophilic radical followed by protonation affords the alkylated product, closing the catalytic cycle. The role of $\mathrm{N}$ substituent in $\mathbf{1}$ as a tethered redox mediator is further supported by additional theoretical study (see the Supporting Information): evaluation of the ionization potential (IP) for the tertiary amine moiety and the aromatic moiety of each catalyst indicated that catalysts with electron-rich aromatic groups $(\mathbf{1 c}-\mathbf{d}, \mathbf{1} \mathbf{g - h})$ have

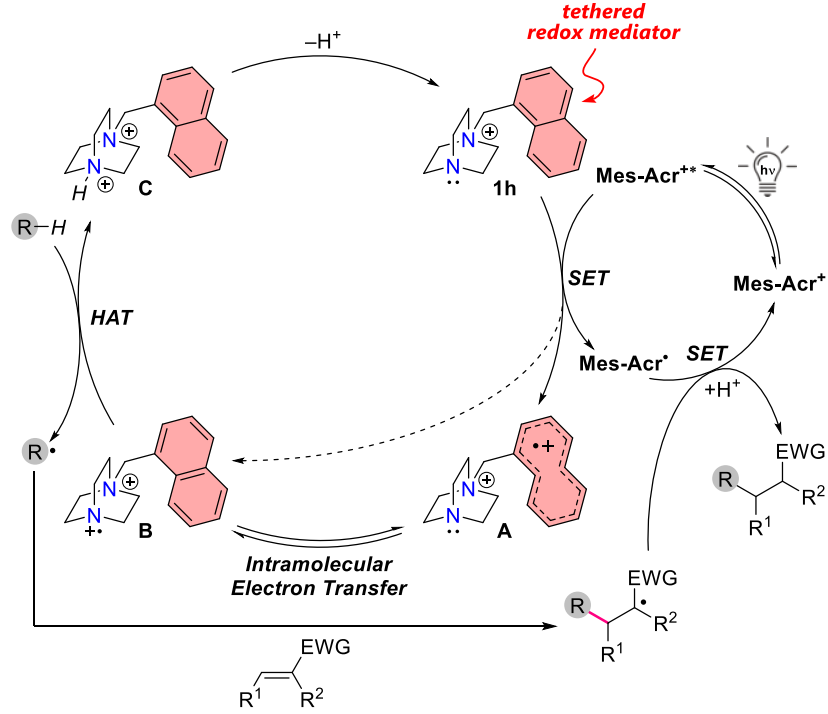

Figure 5. Proposed mechanism using the optimal catalyst $1 \mathrm{~h} . \mathrm{EWG}=$ electronwithdrawing group.

lower IP values for the aromatic moiety than for tertiary amine moiety, while the opposite is true for the other catalysts $(\mathbf{1} \mathbf{a}-\mathbf{b}$, $\mathbf{1 e - f ) . ~ T a k i n g ~ t h e s e ~ r e s u l t s ~ i n t o ~ c o n s i d e r a t i o n , ~ t h e ~ t h e o r e t i c a l ~}$ yield of $\mathbf{3}$ can be described as a function of the IP and the $\mathrm{N}^{+}-\mathrm{H}$ $\mathrm{BDE}$ of each catalyst. We found that these calculated yields for each catalyst have a good correlation with the experimental results, which reinforces the validity of our proposed catalytic cycle based on the intramolecular electron transfer pathway.

In summary, we have developed a novel class of HAT catalysts 1 based on the readily accessible DABCO platform. These catalysts can be synthesized via a facile and modular protocol and show high catalytic efficiency toward visible-lightinduced HAT alkylation of a variety of substrates, including complex molecules. Moreover, the ability of the dicationic aminium radical derived from 1 to act as a site-selective HAT species based on steric differentiation was well demonstrated in the $\mathrm{C}-\mathrm{H}$ alkylation of several compounds containing more than two reactive sites. A series of mechanistic studies indicated that the $\mathrm{N}$-substituent of the catalyst plays a crucial role as a tethered redox mediator to assist in the efficient generation of the dicationic aminium radical. The application of these catalysts to other photoinduced transformations, as well as the development of a novel organoradical catalyst based on the present catalyst design, is ongoing in our laboratory.

\section{Acknowledgements}

K.M. gratefully acknowledge financial support via JSPS KAKENHI grants No. JP17H06450 and JP21H05026. A.M. is thankful for financial support via JSPS KAKENHI grant No. 20K22527. The authors also acknowledge Prof. Dr. Shigeyoshi Sakaki and Dr. Bo Zhu (Fukui Institute for Fundamental Chemistry, Kyoto University) for DFT calculation and Dr. Masanori Yamamoto (Graduate School of Pharmaceutical Sciences, Kyoto University) for cyclic voltammetry measurements. 


\section{Conflict of Interest}

The authors declare no competing financial interest.

Keywords: hydrogen-atom transfer $\cdot$ photoredox catalysis • aminium radical $\cdot \mathrm{C}-\mathrm{H}$ alkylation $\cdot$ redox mediator

[1] For reviews on hydrogen-atom transfer, see: a) Hydrogen-Transfer Reactions (Eds.: J. T. Hynes, J. P. Klinman, H.-H. Limbach,R. L. Schowen), Wiley-VCH Verlag GmbH \& Co. KGaA, 2007; b) J. W. Darcy, B. Koronkiewicz, G. A. Parada, J. M. Mayer, Acc. Chem. Res. 2018, 51, 2391-2399; c) J. M. Mayer, Acc. Chem. Res. 2011, 44, 36-46.

[2] For reviews on $\mathrm{C}-\mathrm{H}$ transformations via HAT, see: a) $\mathrm{H}$. Cao, X. Tang, H. Tang, Y. Yuan, J. Wu, Chem Catalysis 2021, 1, 523-598; b) L. Capaldo, D. Ravelli, M. Fagnoni, Chem. Rev. 2021, DOI 10.1021/acs.chemrev.1c00263; c) L. Capaldo, L. L. Quadri, D. Ravelli, Green Chem. 2020, 22, 3376-3396; d) L. Capaldo, D. Ravelli, Eur. J. Org. Chem. 2017, 2017, 2056-2071; e) S. Protti, M. Fagnoni, D. Ravelli, ChemCatChem 2015, 7, 1516-1523.

[3] S. J. Blanksby, G. B. Ellison, Acc. Chem. Res. 2003, 36, 255-263.

[4] For the polar effect, see: a) A. A. Zavitsas, J. A. Pinto, J. Am. Chem. Soc. 1972, 94, 7390-7396; b) B. P. Roberts, Chem. Soc. Rev. 1999, 28 , 25-35. For the steric effect, see: c) D. C. Eisenberg, C. J. C. Lawrie, A. E. Moody, J. R. Norton, J. Am. Chem. Soc. 1991, 113, 4888-4895; d) T. Gunasekara, G. P. Abramo, A. Hansen, H. Neugebauer, M. Bursch, S. Grimme, J. R. Norton, J. Am. Chem. Soc. 2019, 141, 1882-1886.

[5] a) M. S. Chen, M. C. White, Science 2010, 327, 566-571; b) P. E. Gormisky, M. C. White, J. Am. Chem. Soc. 2013, 135, 14052-14055; c) G. Olivo, G. Farinelli, A. Barbieri, O. Lanzalunga, S. Di Stefano, M. Costas, Angew. Chem. Int. Ed. 2017, 56, 16347-16351; Angew. Chem. 2017, 129, 16565-16569; d) C. Le, Y. Liang, R. W. Evans, X. Li, D. W. C. MacMillan, Nature 2017, 547, 79-83; e) D. Ravelli, M. Fagnoni, T. Fukuyama, T. Nishikawa, I. Ryu, ACS Catal. 2018, 8, 701-713; f) H. Huang, Z. M. Strater, T. H. Lambert, J. Am. Chem. Soc. 2020, 142, 1698-1703.

[6] For selected examples, see: a) S. Mukherjee, B. Maji, A. Tlahuext-Aca, F. Glorius, J. Am. Chem. Soc. 2016, 138, 16200-16203; b) H. Tanaka, K. Sakai, A. Kawamura, K. Oisaki, M. Kanai, Chem. Commun. 2018, 54, 3215-3218; c) T. Wakaki, K. Sakai, T. Enomoto, M. Kondo, S. Masaoka, K. Oisaki, M. Kanai, Chem. Eur. J. 2018, 24, 8051-8055; d) H.-P. Deng, Q. Zhou, J. Wu, Angew. Chem. Int. Ed. 2018, 57, 12661-12665; Angew. Chem. 2018, 130, 12843-12847; e) S. Rohe, A. O. Morris, T. McCallum, L. Barriault, Angew. Chem. Int. Ed. 2018, 57, 15664-15669; Angew. Chem. 2018, 130, 15890-15895; f) K. A. Margrey, W. L. Czaplyski, D. A. Nicewicz, E. J. Alexanian, J. Am. Chem. Soc. 2018, 140, 4213-4217; g) A. S. H. Ryder, W. B. Cunningham, G. Ballantyne, T. Mules, A. G. Kinsella, J. Turner-Dore, C. M. Alder, L. J. Edwards, B. S. J. McKay, M. N. Grayson, A. J. Cresswell, Angew. Chem. Int. Ed. 2020, 59, 1498614991; Angew. Chem. 2020, 132, 15096-15101; h) K. Ohmatsu, R. Suzuki, Y. Furukawa, M. Sato, T. Ooi, ACS Catal. 2020, 10, 2627-2632; i) P. Jia, Q. Li, W. C. Poh, H. Jiang, H. Liu, H. Deng, J. Wu, Chem 2020, 6, 1766-1776; j) Z.-Y. Ma, M. Li, L.-N. Guo, L. Liu, D. Wang, X.-H. Duan, Org. Lett. 2021, 23, 474-479; k) Y. Shen, I. Funez-Ardoiz, F. Schoenebeck, T. Rovis, J. Am. Chem. Soc. 2021, DOI 10.1021/jacs.1c07144

[7] a) K. Kwon, R. T. Simons, M. Nandakumar, J. L. Roizen, Chem. Rev. 2021, DOI 10.1021/acs.chemrev.1c00444; b) G. Kumar, S. Pradhan, I. Chatterjee, Chem. Asian J. 2020, 15, 651-672; c) H. Jiang, A. Studer, CCS Chemistry 2019, 38-49.

[8] W. Xiao, X. Wang, R. Liu, J. Wu, Chin. Chem. Lett. 2021, 32, 18471856.

[9] F. J. Aguilar Troyano, K. Merkens, A. Gómez-Suárez, Asian J. Org. Chem. 2020, 9, 992-1007.

[10] a) D. D. Bume, C. R. Pitts, F. Ghorbani, S. A. Harry, J. N. Capilato, M. A. Siegler, T. Lectka, Chem. Sci. 2017, 8, 6918-6923; b) H. Egami, S. Masuda, Y. Kawato, Y. Hamashima, Org. Lett. 2018, 20, 1367-1370; c) F. Ghorbani, S. A. Harry, J. N. Capilato, C. R. Pitts, J. Joram, G. N.
Peters, J. D. Tovar, I. Smajlagic, M. A. Siegler, T. Dudding, T. Lectka J. Am. Chem. Soc. 2020, 142, 14710-14724; d) J. Zhou, Y. Zou, P Zhou, Z. Chen, J. Li, Org. Chem. Front. 2019, 6, 1594-1598.

[11] For reviews, see: a) P. T. Nyffeler, S. G. Durón, M. D. Burkart, S. P. Vincent, C.-H. Wong, Angew. Chem. Int. Ed. 2005, 44, 192-212; Angew. Chem. 2005, 117, 196-217; b) S. Stavber, Molecules 2011, 16, 6432 6464; c) B. Lantaño, A. Postigo, Org. Biomol. Chem. 2017, 15, 9954 9973.: For selected examples, see: d) Q. Michaudel, D. Thevenet, P. S Baran, J. Am. Chem. Soc. 2012, 134, 2547-2550; e) G. B. Boursalian, W. S. Ham, A. R. Mazzotti, T. Ritter, Nat. Chem. 2016, 8, 810-815; f) C. R. Pitts, B. Ling, J. A. Snyder, A. E. Bragg, T. Lectka, J. Am. Chem. Soc. 2016, 138, 6598-6609; g) F. J. Aguilar Troyano, F. Ballaschk, M. Jaschinski, Y. Özkaya, A. Gómez-Suárez, Chem. Eur. J. 2019, 25 , 14054-14058; h) L. Niu, J. Liu, X.-A. Liang, S. Wang, A. Lei, Nat Commun. 2019, 10, 467; i) X.-A. Liang, L. Niu, S. Wang, J. Liu, A. Lei, Org. Lett. 2019, 21, 2441-2444; j) H. Zhao, J. Jin, Org. Lett. 2019, 21 , 6179-6184.

[12] N. A. Romero, K. A. Margrey, N. E. Tay, D. A. Nicewicz, Science 2015, 349, 1326-1330.

[13] a) J. L. Jeffrey, J. A. Terrett, D. W. C. MacMillan, Science 2015, 349, 1532-1536; b) V. Dimakos, H. Y. Su, G. E. Garrett, M. S. Taylor, J. Am. Chem. Soc. 2019, 141, 5149-5153; c) K. Sakai, K. Oisaki, M. Kanai, Adv. Synth. Catal. 2020, 362, 337-343; d) Sakai, K. Oisaki, M. Kanai Synthesis 2020, 52, 2171-2189; e) D. J. Gorelik, J. A. Turner, T. S. Virk, D. A. Foucher, M. S. Taylor, Org. Lett. 2021.

[14] S. Mukherjee, R. A. Garza-Sanchez, A. Tlahuext-Aca, F. Glorius, Angew. Chem. Int. Ed. 2017, 56, 14723-14726; Angew. Chem. 2017, 129, 14915-14919.

[15] C. M. Morton, Q. Zhu, H. Ripberger, L. Troian-Gautier, Z. S. D. Toa, R. R. Knowles, E. J. Alexanian, J. Am. Chem. Soc. 2019, 141, 1325313260.

[16] The oxidation potential of $N$-chloromethyl substituted catalyst 1a has recently been reported. See ref $10 \mathrm{c}$

[17] W.-Z. Liu, F. G. Bordwell, J. Org. Chem. 1996, 61, 4778-4783.

[18] Several aromatic compounds have been used as an exogenous electron mediator in photoredox catalysis. For example, see: a) T. Tamai, N. Ichinose, T. Tanaka, T. Sasuga, I. Hashida, K. Mizuno, J. Org. Chem. 1998, 63, 3204-3212; b) G. Gutenberger, E. Steckhan, S. Blechert, Angew. Chem. Int. Ed. 1998, 37, 660-662; c) M. Riener, D. A Nicewicz, Chem. Sci. 2013, 4, 2625-2629; d) S. Kubosaki, H. Takeuchi, Y. Iwata, Y. Tanaka, K. Osaka, M. Yamawaki, T. Morita, Y. Yoshimi, J. Org. Chem. 2020, 85, 5362-5369.

[19] For the use of aromatic groups as a redox tag to probe an intramolecular SET process, see: N. Maeta, H. Kamiya, Y. Okada, Org. Lett. 2019, 21 , 8519-8522. 


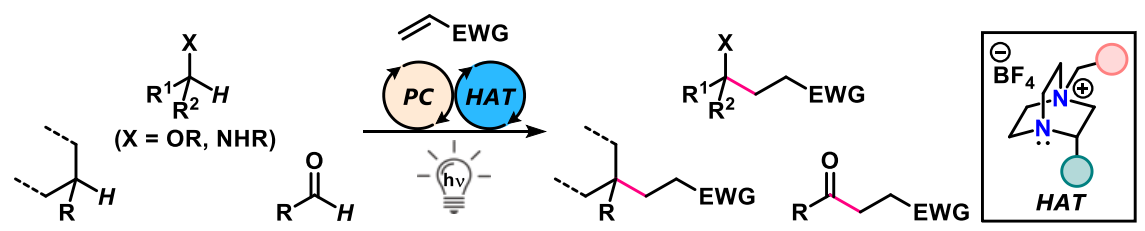

A novel hydrogen-atom transfer (HAT) catalysts based on readily accessible 1,4-diazabicyclo[2.2.2]octane (DABCO) was developed. These catalysts enable efficient and site-selective $\mathrm{C}-\mathrm{H}$ alkylation of various substrates via visible-light-induced HAT in combination with an organophotoredox catalyst. Mechanistic studies suggested that the $\mathrm{N}$-substituent of the catalyst plays a crucial role, assisting in the generation of the dicationic aminium radical. 